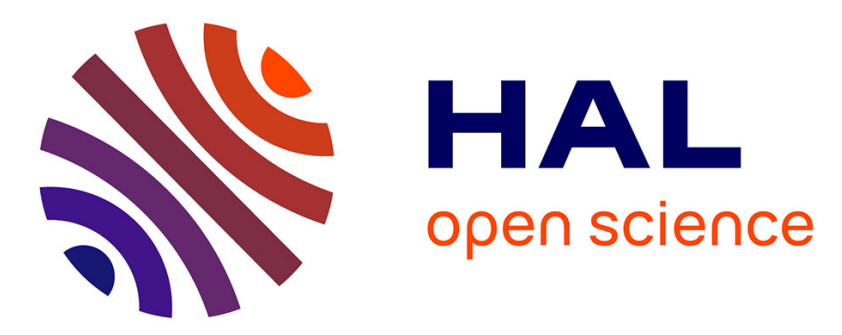

\title{
Three-dimensional closed microfluidic channel fabrication by stepper projection single step lithography: the diabolo effect
}

Florian Larramendy, Laurent Mazenq, Pierre Temple-Boyer, Liviu Nicu

\section{- To cite this version:}

Florian Larramendy, Laurent Mazenq, Pierre Temple-Boyer, Liviu Nicu. Three-dimensional closed microfluidic channel fabrication by stepper projection single step lithography: the diabolo effect. Lab on a Chip, 2012, 12 (2), pp.387-390. 10.1039/C1LC20810A . hal-01511362

HAL Id: hal-01511362

https://hal.laas.fr/hal-01511362

Submitted on 20 Apr 2017

HAL is a multi-disciplinary open access archive for the deposit and dissemination of scientific research documents, whether they are published or not. The documents may come from teaching and research institutions in France or abroad, or from public or private research centers.
L'archive ouverte pluridisciplinaire HAL, est destinée au dépôt et à la diffusion de documents scientifiques de niveau recherche, publiés ou non, émanant des établissements d'enseignement et de recherche français ou étrangers, des laboratoires publics ou privés. 


\title{
Three-dimensional closed microfluidic channels fabrication by stepper projection single step lithography: the Diabolo effect
}

\author{
F. Larramendy ${ }^{\mathrm{a}, \mathrm{b}}$, L. Mazenq ${ }^{\mathrm{a}, \mathrm{b}}$, P. Temple-Boyer ${ }^{\mathrm{a}, \mathrm{b}}$, L. Nicu ${ }^{\mathrm{a}, \mathrm{b}}$
}

DOI: 10.1039/b000000x

Microfluidic devices are currently being used in many types of biochemical microsystems for the liquid phase analysis in the frame of medical applications. This paper presents a new technique for the realization of microfluidic channels using SU-8, a commonly used epoxy-based negative photo-resist. These microchannels were fabricated owing to a single stepper UV-photolithography process. By changing the process parameters, e.g. the optical focus depth and the UV exposure dose, well-defined, covered microchannels with various dimensions and aspect ratios were realized and proven to be effective for the fluid transport by capillarity. This technique can easily be used for the fabrication of microfluidic devices in microanalysis and lab-on-chip applications realm.

\section{Introduction}

The SU-8 product line consists of chemically amplified, epoxy based negative resists with high functionality, high optical transparency and sensitivity to near ultraviolet (UV) radiations ${ }^{1,2}$. Cured SU-8 films and related topographies are highly resistant to solvents, acids and bases and have excellent thermal stability, making them well suited for permanent use applications $^{3}$. Furthermore, since biocompatibility was demonstrated ${ }^{4}$, they were commonly used for the development of micro/nanosystems in the frame of mechanical, fluidic, optical and biological applications. SU-8 is also used to fabricate three-dimensional microstructures ${ }^{5}$. However, main works concerned the realization of Bio-MEMS (biological micro-electromechanical systems) used in lab-on-chip ${ }^{6-8}$ and microanalysis applications, emphasizing the technological integration of closed microfluidic channels with optimized properties.

\begin{abstract}
Among the different techniques developed for the mass fabrication of SU-8 microfluidic channels, lamination is the most widely used one. It consists in reporting one photoresist layer on another one used as main support. The bilayer structure is finally compressed and heated up between two rolls in order to form a unique SU-8 layer ${ }^{9}$. Such process is quite convenient and allows the creation of SU-8 multilayers ${ }^{10}$. With this method, losses of photoresist products are negligible compared to the conventional deposition process by spin coating ${ }^{11}$. Moreover, it enables a greater control and reliability of the top cover. Yet, a lithography step is required for patterning each SU-8 layer meaning that at least two such steps are necessary to fabricate closed microchannels.

Another technique is based on a double UV exposure but using only one SU-8 layer ${ }^{12}$. The first exposure is performed for a given mask, wavelength and duration in order to pattern the microchannels. The second one makes use of another mask, wavelength and duration to realize their openings. Thus, by combining these two different photolithography processes, it is possible to control the SU-8 cover thickness ${ }^{13-15}$. Nevertheless, if the main advantage of this technique is related to the use of a single SU-8 layer, it stills requires two photolithographic steps with two different masks.
\end{abstract}

To reduce the mask number to one, another technique proposes optimized mask displacements in order to modulate the UV exposure of the SU-8 layer according to a predefined pattern ${ }^{16}$. This method allows the fabrication of microchannels in a single step but requires in exchange complex technical adaptation of the UV lithographic equipment.

In this technical note, we introduce a new technique to fabricate such closed microfluidic channels while using a single photolithographic mask, a single SU-8 layer and standard commercial equipments based on the "optical lithography by projection" technology. The technique is potentially easy-to-implement on demand as the last fabrication step in the process flow of already structured wafers either for flow-through or sealing purposes ${ }^{17}$.

\section{Experimental}

The optical lithography by projection, also called "stepper" technology, consists in exposing a photosensitive resist through a complex optical system acting as a reduction lens ${ }^{18,19}$. In such equipment developed by the ASML company (figure 1), the photolithographic mask is placed far from the substrate ( 0.2 to 1 meter) compared to conventional UV mask aligners where the mask-substrate distance ranges from 0 to less than 1 millimeter. The mask pattern is optically projected on the photosensitive layer while scaled down by a factor that commonly reaches ten. 


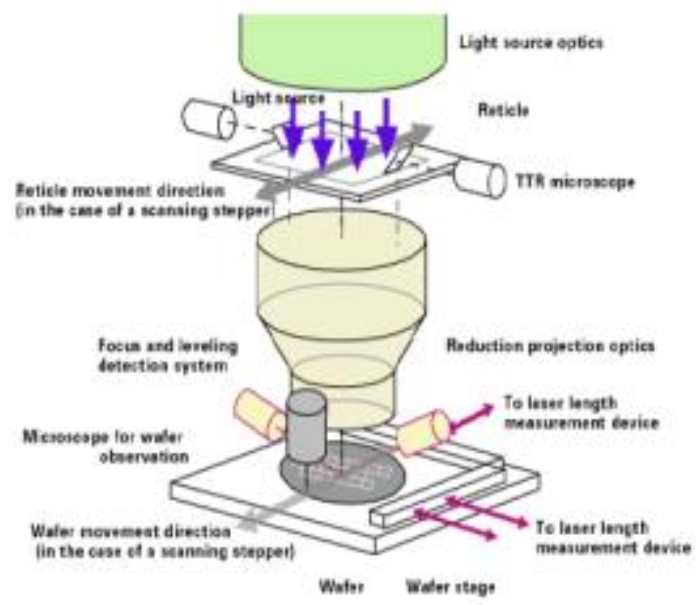

Figure 1. Design of the ASML stepper lithography canon FPA 3000 i4

The main parameters of the stepper lithography process are related to the exposure dose $d_{\text {exp }}$ and the focus depth $d_{f}$. In our experiment, exposure dose variations are obtained by combining the exposure duration and the illumination aperture using a constant UV (wavelength: $365 \mathrm{~nm}$ ) illumination power. Concerning the focus depth $\mathrm{d}_{\mathrm{f}}$, it can be modified from +50 to -50 microns according to the positioning of the optical lens towards the wafer. In the standard use, the reticule is focalised in the middle of the resist film $\left(\mathrm{d}_{\mathrm{f}}=0\right)$, defining a "diabolo-like" UV illumination characterized by a typical angle $\theta_{1}$ (figure 2 ). This angle could be easily related to the largest angle for the light incident rays $\theta_{0}$ according to the Descartes law: $n \cdot \sin \theta_{1}=\sin \theta_{0}$, where $\mathrm{n}$ is refractive index of the photoresist film (nsus $=1.58$ at $365 \mathrm{~nm}$ ).

However, in a non-standard use and by decreasing the focus depth towards negative values, it was possible to focus the reticule in the upper part of the resist film, leading to an UV exposure imbalance between its upper and lower parts. As a result, this "diabolo effect" allowed the definition of three-dimensional conical, pyramidal and/or triangular patterns with various sizes and geometries.

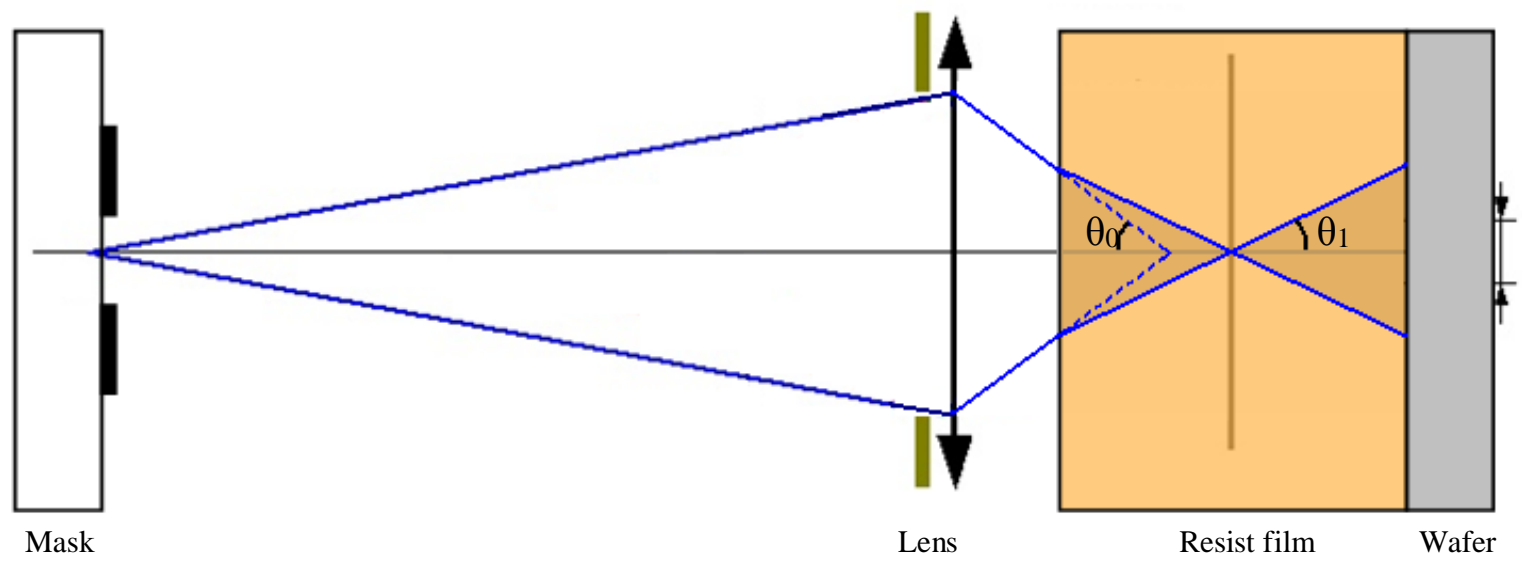

Figure 2. Principle of the optical lithography projection and associated "diabolo effect"

In order to study this "diabolo effect", a "stepper" test mask was realized. It involves lines with widths ranging from 1 to 20 microns and lengths ranging from 250 to 1000 microns. Each line ends by an "OK" symbol that allows to check the microchannel's liquid flowing effectiveness.

First, the "diabolo effect" was studied for the standard AZ4562 photoresist (thickness: 10um) and related exposure/development processes. Then, these basic technological researches were extended to SU-8, a commonly used epoxy-based negative photoresist. Different SU-8 layers (thickness: 25, 50 and 100) were spin-coated on $\langle 100\rangle$ silicon wafers, patterned using the "stepper" technique, and revealed chemically using a Propylene Glycol Methyl Ether Acetate (PGMEA) standard solution. Although interesting results were obtained for each SU-8 thickness (see hereafter), an in-depth study is first presented for the $50 \mu \mathrm{m}$ thickness. The following process was especially used for patterning such SU-8 layers:

- deposition by spin coating (speed: 1450 round per minute (rpm), acceleration: $5000 \mathrm{rpm} / \mathrm{s}$ and a duration: $30 \mathrm{~s}$ )

- $\quad$ pre-annealing on heating plate (temperature: $95^{\circ} \mathrm{C}$, duration: $45 \mathrm{~min}$ )

- UV exposure (dose: $1000 \mathrm{~J} / \mathrm{m}^{2}$ )

- post-annealing on heating plate (temperature: $95^{\circ} \mathrm{C}$, duration: $3 \mathrm{~min}$ )

- development with PGMEA (duration: 20min) 
- last annealing on heating plate (temperature: $125^{\circ} \mathrm{C}$, duration: $2 \mathrm{~min}$ )

To characterize the fabricated microchannels, several methods were used. Their geometry and dimensions were controlled and measured by Scanning Electron Microscopy (SEM) observations using a Hitachi S-4800. Then, after a specific oxygen plasma treatment $(200 \mathrm{~W}, 30 \mathrm{~s})$, the hydrophilicity was estimated using optical microscopy using a Leica DM4000M. Finally, the fluidic continuity was checked by optical microscopy thanks to the correct filling with colored ink of the "OK" pattern (see below).

\section{Results and discussion}

Having demonstrated the "diabolo effect" by making use of an easy-to-process photoresist (AZ4562 - see figure S1, Supplementary Information), the work was then shifted to the SU-8 one. As first qualitative results, it appears that too high focus depth values lead to no-covered microchannels while too small values lead to no-opened ones, particularly for the lower SU-8 thicknesses illustrated in figure 3.

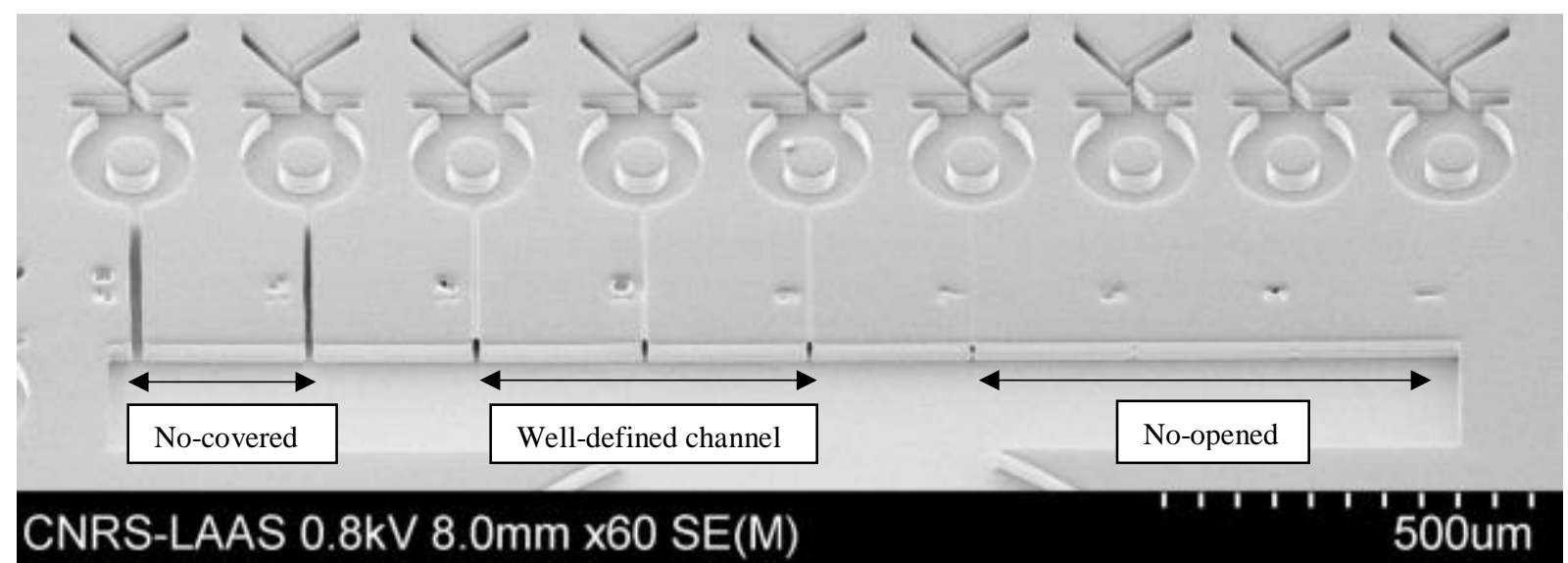

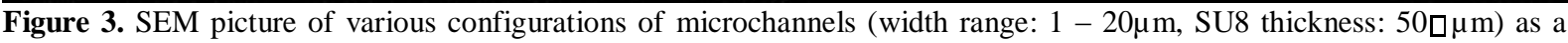
function of the focus depth value

Yet, the "diabolo effect" allowed the obtaining of "well-defined", dome-like shaped microchannels whose height depends on the way the focus depth value is tuned (Figure 4).

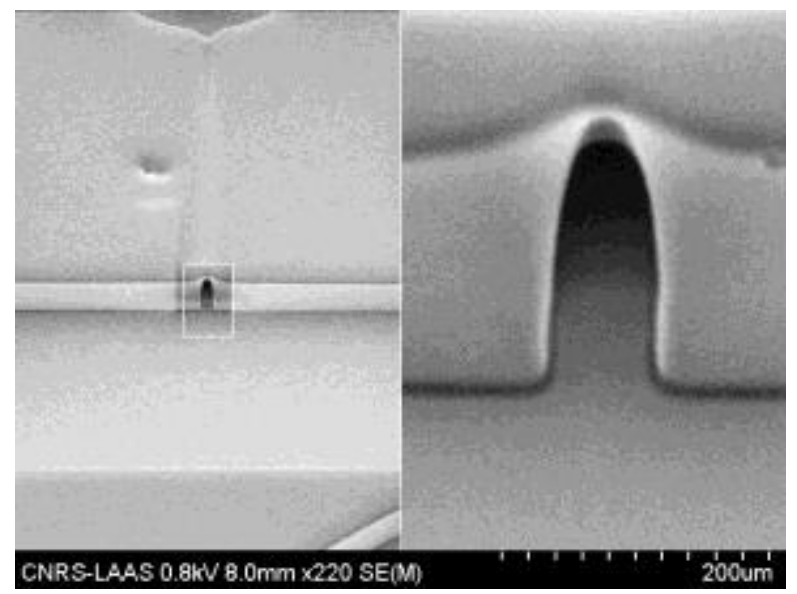

Figure 4. SEM of a 50 $\mu \mathrm{m}$-height, $15 \mu \mathrm{m}$-wide microchannel and zoom on the channel's entrance

To gain further insight on the parameters that mainly impact the "diabolo effect" effectiveness, a through study was performed on $10 \mu \mathrm{m}$ and $15 \mu \mathrm{m}$-wide, $50 \mu \mathrm{m}$-thick SU8 patterns. The influence of the main exposure parameters, e.g. the focus depth $\mathrm{d}_{\mathrm{f}}$ and the exposure dose $\mathrm{d}_{\mathrm{exp}}$, are presented on figures 5 and 6 for such conditions. It appears that the microchannel height decreases with the focus depth increase while the focus depth impacts less the microchannel's width except for the highest values (higher than $-25 \mu \mathrm{m}$ ) (figure 6). Eventually, if the exposure dose has little influence on the microchannel's width, it dramatically influences its height (figure 6). As a result, by tuning simultaneously both parameters, it should be possible to precisely control the microchannel's three-dimensional geometry. 

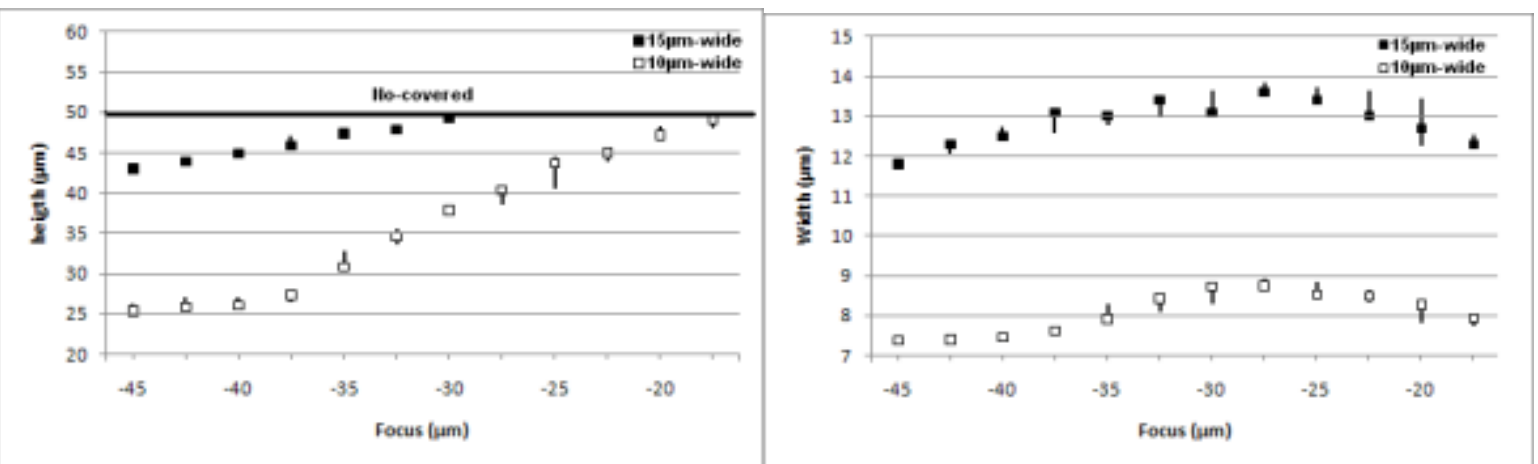

Figure 5. Microchannel width (left) and height (right) according to the focus depth for a $15 \mu \mathrm{m}$-wide and $10 \mu \mathrm{m}$-wide exposure line in a 50 $\mu$ m-thick SU-8 layer (measures performed on six different chips).
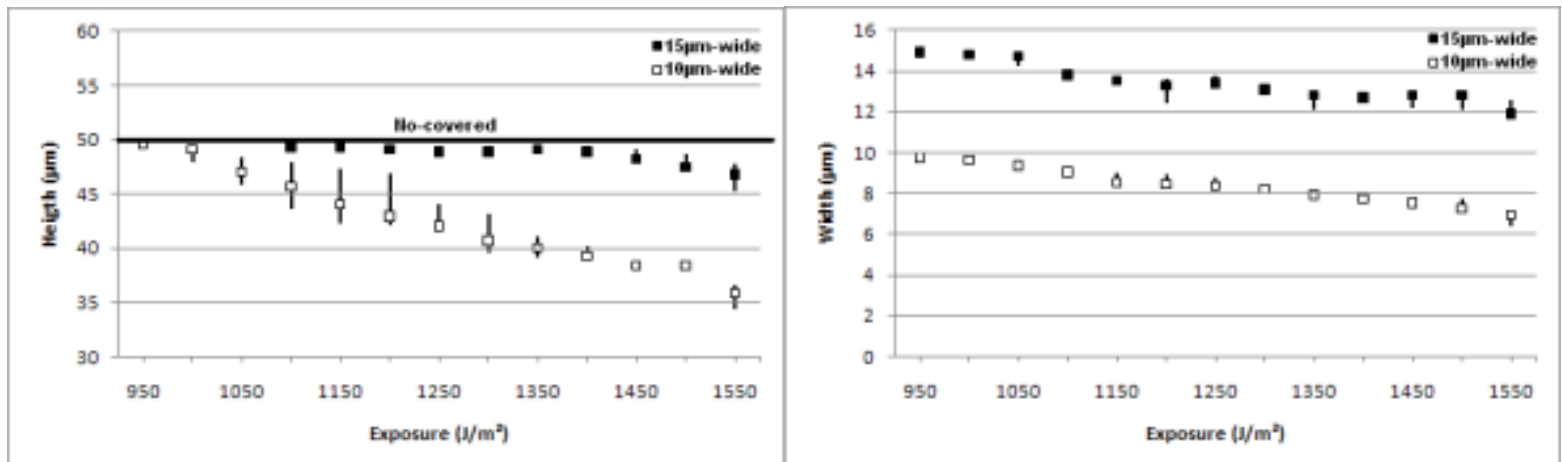

Figure 6. Microchannel width (left) and height (right) according to the exposure dose for a $15 \mu \mathrm{m}$-wide and $10 \mu \mathrm{m}$-wide exposure line in a 50 $\mu$ m-thick SU-8 layer (measures performed on six different chips).

After optimizing the exposure dose $d_{\exp }$ and the focus depth $d_{f}$ parameters, microchannels with various widths, i.e. ranging from 5 to 20 microns (figure S2, Supplementary Information) as well as networks of microchannels at the wafer scale (figure S3, Supplementary Information) were successfully fabricated into 50 $\mu \mathrm{m}$-thick SU8-layer.

Finally, capillary tests were performed to confirm the liquid flowing through the microchannels. Following a specific oxygen plasma treatment to render the SU-8 hydrophilic, blue ink droplets were deposited at one extremity of each microchannel and revealed an inked "OK" at the opposite extremity in case of successful flow-through. Such tests were performed successfully with a high reproducibility for straight microchannels with lengths ranging from 0.25 to 10 millimeters (256 different patterns/wafer), and successfully extended to 5mm-long, S-shaped microchannels (figure 7).
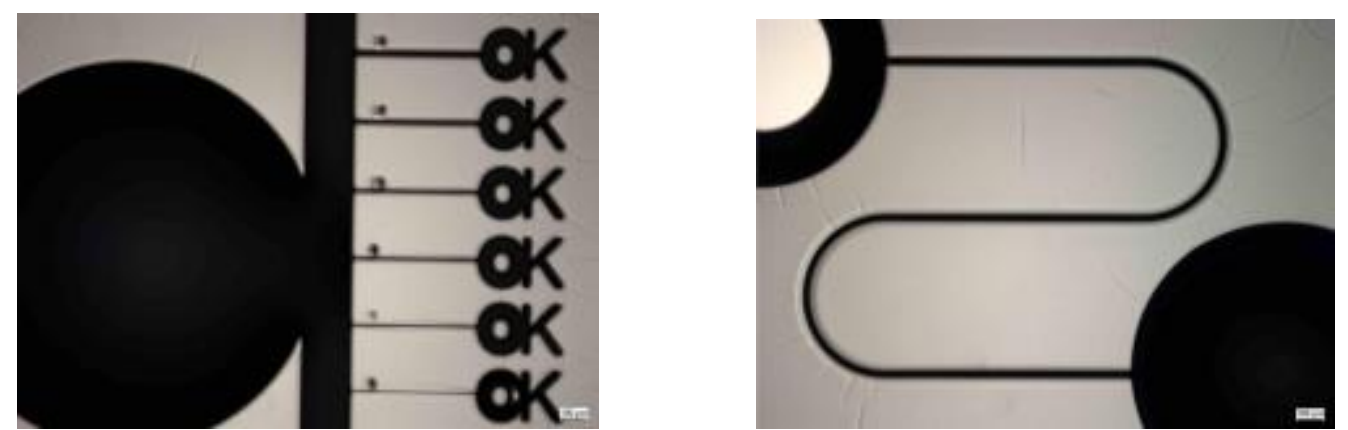

Figure 7. Capillarity test with blue ink in straight (left) and serpentine (right) lines (optical microscope images)

\section{Conclusions}

In this paper, the "stepper technology" was used in a non-standard way in order to fabricate SU-8 based, microfluidic channels owing to a single UV-lithography process while using the so-called "diabolo effect". By studying the influence of the main parameters, e.g. the optical focus depth and the UV exposure dose, the lithographic technological process was optimized. Thus, well-defined, covered microchannels were realized with various sizes and geometries. Typical dimensions involve width ranging from 3 to 20 microns, length reaching 1 centimeter, in SU8 resin film thickness ranging from 25 to 200 microns. Finally, using specific oxygen plasma treatment to render the SU-8 hydrophilic, such microchannels were proven to be effective for the fluid transport by capillarity. As a result, this "stepper" technique was successfully used for the fabrication of numerous microfluidic devices and has therefore great interest for the realization of lab-on-chip in the frame of medical analysis. 


\section{References}

a CNRS; LAAS; 7 avenue du colonel Roche, F-31077 Toulouse, France

b Université de Toulouse; UPS, INSA, INP, ISAE; LAAS; F-31077 Toulouse, France

1 W.J. Kang, E. Rabe, S. Kopetz and A. Neyer Journal of Micromechanics and Microengineering 2006, 16, 821-831.

2 S. Salomon, T. Leichle, L. Nicu Electrophoresis 2011, 32, 1508-1514.

3 A. Del Campo and C. Greiner Journal of Micromechanics and Microengineering 2007, 17, R81-R95.

4 V.N Vernekar, D. Kacy Cullen, N. Fogleman, Y. Choi, A.J. Garcia, M.G. Allen, G.J. Brewe, M.C. LaPlaca Journal of Biomedical Materials Research Part A, 2009, 89, 138-151.

5 J.K Kim, M.G. Allen, Y.K. Yoon, Journal of Micromechanics and Microengineering 2011, 21, 035003.

6 L. Nicu and T. Leichle, Journal of Applied Physics 2008, 104, 111101

7 T. Leichle, D. Saya, JB. Pourciel, F. Mathieu, L. Nicu, C. Bergaud, Sensors and Actuators Physical-A 2006, 132, 590-596

8 L. Nicu and C. Bergaud, Journal of Applied Physics 1999, 89, 5835-5840

9 P. Abgrall, S. Charlot, R. Fulcrand, P. Lefillastre, A. Boukabache, A.M. Gue Microsystem Technologies 2008, 14, 8, 1205-1214.

10 P. Abgrall, C. Lattes, V. Conedera, X. Dollat, S. Colin and A.M. Gue Journal of Micromechanics and Microengineering 2005, 16, 113121.

11 P. Temple-Boyer, L. Mazenq, J.B. Doucet, V. Conedera, B. Torbiero, J. Launay Microelectronic Engineering 2010, 87, 163-166.

12 C. Fu, C. Hung and H. Huang Journal of Physics : Conference Series 2006, 34, 330-335.

13 F. Ceyssens and R. Puers Journal of Micromechanics and Microengineering 2006, 16, S19-S23.

14 M. Gaudet, J.C. Camart, L. Buchaillot and S. Arscott Applied Physics Letters 2006, 88, 024107.

15 J.M. Dykes, D.K. Poon, J. Wang, D. Sameoto, J.T.K. Tsui, C. Chinheng Choo, G.H. Chapman, A.M. Parameswaren and B.L. Gray Proc. of SPIE 2007, 6465, 64650.

16 Y. Hirai, K. Sugano, T. Tsuchiya and O. Osamu Tabata Journal of Microelectromechanical Systems 2010, 19, 1058-1069.

17 MF. Khan, S. Schmid, ZJ. Davis, S. Dohn and A. Boisen, Microelectronic Engineering 2011, 88, 2300-2303

18 Levinson HJ Principles of Lithography Third Edition SPIE PRESS, 2010.

19 Lin BJ Optical Lithography Here is Why SPIE PRESS, 2010. 